\title{
Role of Knowledge Reusability in Technological Environment During Learning
}

\author{
O. K. Harsh \\ Group Director, \\ Amritsar College of Engineering \& Technology, \\ Amritsar, India
}

\begin{abstract}
Role of technology and reusability on the knowledge management and knowledge transformation has been analyzed by considering the extended model of Nonaka and Takeuchi which includes the knowledge reuse in the three dimensional environment. Knowledge transformation has been further refined (and boosted) to get the more qualitative and quantitative knowledge by applying the concept of knowledge reification, indexing and adaption. By extending these concepts and related processes, ADRI quality model on higher education learning has been analyzed. Present work suggest that reusability along with above mentioned concepts during ADRI cycle can boost the qualitative knowledge in higher educational setting and observed that ADRI model has the similar trends as that of Nonaka model in the three dimensional environments. In addition, discussion also prevails that best practices required in a higher educational setting correspond to ADRI model.
\end{abstract}

It has been suggested that time along with reusability supports to the tacit as well as explicit knowledge management during learning. The knowledge transformation achieved this way is more qualitative. Finally it can be concluded that tacit and explicit knowledge required to reuse is an important aspect now days in managing higher educational knowledge in a fast growing contemporary environment provided knowledge is exploited appropriately.

Keywords-Knowledge; Reuse; Tacit Knowledge; Explicit Knowledge; Technology; ADRI model; Quality

\section{INTRODUCTION}

Managing knowledge has been becoming a competitive advantage in a global economy. Many companies have been engaged in identifying, managing and sharing experience of employees [1, 2]. Most of the companies involved in the electronic management of knowledge so that they can enhance their capability to manage vast knowledge hidden within the organization [3]. However, we now realize that managing knowledge is more difficult than previously thought. Krogh et al. [4] studied the knowledge reuse in open source software projects. They found that behaviour factors are responsible for the form of the knowledge reuse.

According to Hedlund [5], there are four different levels of carriers of knowledge which are individual, the small group, the organization and the inter-organizational domain (important customers, suppliers competitors, etc.). Hedlund [5] further suggested that each carrier is having different forms or aspects of knowledge egg, cognitive knowledge in the form of mental constructs and precepts, skills and knowledge embodied in products or well-defined service or artifacts. Kusunoki et al. [6] applied the concept of multilayered knowledge to describe organizational capabilities. According to them there are three different layers of knowledge each of them provides different types of capability. They described that "knowledge is the layer that includes distinctive individual units of knowledge (e.g. functional knowledge embodied in a specific group of engineers, databases, patents, etc.)"

Research of Kusunoki et al. [6] describes the features of the managerial potential possessed by every layer which may be observed in two dimensions. First one describes the modularity of the organizational potential, capturing whether organizational potential are supported on individual knowledge components and join every component of knowledge while the second dimension describes the design skill or manageability of organizational capabilities. "This dimension which symbolizes the 'designable knowledge' versus 'embedded knowledge' focuses on whether the management can directly design and control the capabilities" [6].

Work of Nonaka and Konno [9] suggested that there is a gap for knowledge construction in organizations. They mentioned that this gap "can be thought of as a shared space for emerging relationships". According to Nonaka and Konno [9] this space can be either physical (e.g. office, dispersed business space), virtual (e.g. e-mail, teleconference), mental (e.g. shared experiences, ideas, ideals) or any combination of these". They established four diverse forms, which fit into each phase of the SECI model (SECI stands for Socialization, Externalization, Combination and Internalization, which are the familiar four diverse forms of knowledge translation [10]).

Software reuse and software knowledge reuse is an important aspect to describe quality and productivity. Under such processes reuse is a complex procedure and during this procedure it is extremely tricky to choose or forecast suitable kind of metrics to permit an organization to get optimum advantage. It should be noted that arrangement of software component reuse should be suitable to every stage of complete life cycle of the software growth. This can allow us to understand the power and weak points in our knowledge leveraging ability. Technology used in each phase of software development or knowledge transformation can facilitate the process of reuse provided we know that how the reusability varies in the space.

Important question is that what should be the job of the technology for the learners particularly in the conversion of 
one kind of knowledge into (tacit to explicit) a different kind and vice versa as a result of knowledge reusability? How the quality of data, information and knowledge can be enhanced in the Nonaka Model [7, 8] particularly in higher educational learning environments by applying the concept of knowledge reuse, reification, indexing and adaption etc. Another issue is the time obstruct in the $[7,8]$ Nonaka model which is the issue that requires to be suitably answered in the rapid varying technological humanity. An interesting question at this stage could be that how various processes in the refined Nonaka model are useful for higher educational environment? None of the answers of the above questions are available therefore it has decided to work on a framework to correlate all these aspects.

\section{KNOWLEDGE MANAGEMENT AND TECHNOLOGY}

The utilization of technology to administer and hunt compilation of explicit knowledge is well recognized. A case is to employ text categorization to allocate documents mechanically to a topic plan. A characteristic task may be to present a manuscript into a joint database.

It is a fact that technology like the World Wide Web, GPS etc. can enormously boost the allocation of knowledge both inside and outside of organizations. However knowledge management implies further than what we call databases and networks. Companies applying such means have observed that only 20 percent of their complete efforts occupy technical concerns; the residual 80 percent of their time is exhausted with their institutional problems.

Knowledge can only be managed adequately if the issue like technology, human resource practices, organizational structure and culture all are considered together. Because of this fact that we desire to make sure that the correct knowledge is brought to allow at the correct time. The majority of the companies attempt to execute modern technology but then discover that variation of knowledge with time as a result of technological developments is tricky to understand.

The objective of present work is to uncover the processes of reuse, information transfer, coordination and transformation of knowledge by applying Information Technology, internet and associated tools with the variation of time. The issue of quality of knowledge as a result of reuse, reification, indexing and adaption will also be taken into account during learning. For this, models of knowledge management in three dimensional environments as well as an extended ADRI (Approach, Deployment, Result and Improvement) quality model in higher educational environment have been considered where reuse is measured as an explicit quantities. For this we require to begin with the existing knowledge management and knowledge reuse models in the literature such as Nonaka [10] and Nonaka and Takeuchi [11] and Harsh [12-15, 26-28]. In other words the ADRI quality model [18, 22] of higher educational environments has been extended as well elaborated by applying the concepts associated with the revised Nonaka model from two dimensions to three dimensions to uncover useful knowledge transformations and reuse.

Support to the configuration and communication of tacit knowledge (including its reuse), and allow it for transforming into explicit knowledge are currently not a great deal, though numerous optimistic modification may be observed, such as the employing of text-based chat, expertise location, and unrestricted bulletin boards.

To deal the affect of technologies, it is better to categorize the technologies by means of orientation of tacit and explicit knowledge as initiated by Polanyi [16] and employed by Nonaka [10. 11]. This creates a hypothesis of organizational learning. This hypothesis connects the revolution of knowledge amid tacit and explicit shapes. Tacit knowledge implies that that what knower recognizes, which is supported on the practice and consists of reliance and value. Reuse of tacit knowledge is simple and manageable. Tacit knowledge behaves like as an act, and therefore it is extremely significant.

One should remember that tacit knowledge is the largely significant cause for the creation of novel knowledge, because according to Nonaka [10]: "the key to knowledge creation lies in the mobilization and conversion of tacit knowledge."

Explicit knowledge may be signified by some sort of artifact for instance text or a video, which has typically been generated with the objective of communicating with a different individual.

In Knowledge Management, there are three major components [17] which are People, Processes and Technology. People are accountable for creating, sharing, and using knowledge, and who jointly comprise the organizational civilization that takes care for and inspires for the sharing of knowledge. Processes are accountable for acquiring the techniques and creating, organizing, sharing and transferring knowledge while Technology is responsible for the tools for accumulating and supplying right to use data, information, and knowledge generated by people in a variety of settings. Reuse of all these three major components (People, Processes and Technology) is the key to success in a contemporary organization.

\section{DETAILED FORMULATION}

\section{A. Nonaka and Takeuchi Knowledge Management Model}

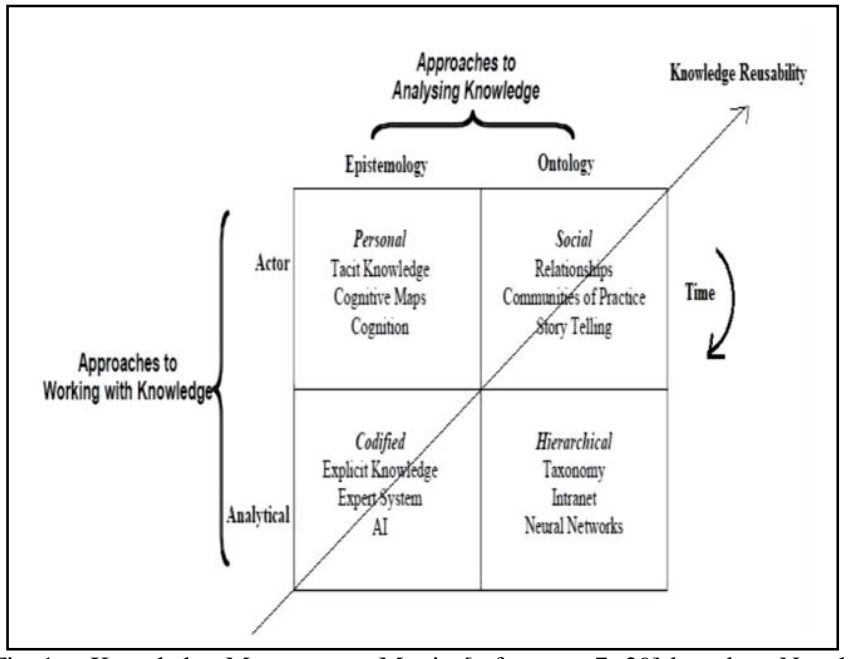

Fig. 1. Knowledge Management Matrix [references 7, 29] based on Nonaka and Takeuchi Model (1995) or SECI Model (Revised by Present Author [References 13-15 ]. 
Nonaka and Takeuchi [10] described the conversions of tacit to explicit knowledge during the socialization, externalization, combination and internalization processes. They mentioned that tacit to explicit and explicit to tacit knowledge is constantly moveable during one or extra procedure in an institute. Moteleb and Woodman [29] submitted a Knowledge Management Model based on the Nonaka model which has been further revised by the present author by inserting reusability and time [15] (see Fig.1).This model identifies the Approaches of working with knowledge and to analyzing knowledge. Likewise, tacit to tacit and explicit to explicit knowledge transfer in a similar way. According to them there is a continual learning procedure in an organization during which knowledge amplified similar to a spiral. Therefore the knowledge is supplemented when shared like Fig. 1. Knowledge relocates amid individuals through information (externalized) "and then converted back from information back to knowledge" (Nonaka and Takeuchi Model [10]).

\section{B. Technology and Proposed Three Dimensional Model based on Nonaka and Takeuchi Model [10]}

In this article it is being suggested that relocation of knowledge definitely takes time and valuable knowledge of an institute boost up during the reuse of knowledge [12-15]. Time behaves as a critical feature for any institute to gather information, to systematize knowledge, to relocate knowledge from one shape to another in constructive shape, therefore the institute has extra knowledge. Harsh suggested that [12-15] time should be measured through an additional axis in Fig. 1 of Nonaka and Takeuchi Model [10]. Enhancement of time improves knowledge in a three dimension (see Fig. 2 below) (through translation from information) similar to a solid cone as mentioned in reference [15]. Such cone consists of all kind of knowledgeof conversion processes as suggested by Nonaka and Takeuchi Model [10] (such as during socialization, externalization, combination and internalization processes).

Both explicit and tacit knowledge can be reused. Therefore we require another axis to symbolize the knowledge reusability.

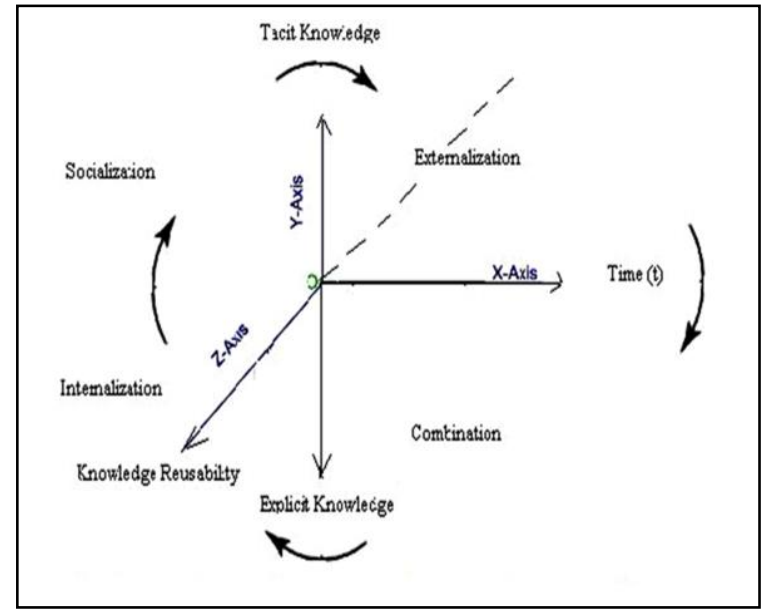

Fig. 2. Extended Nonaka and Takeuchi (1995) Model taken from reference [15].
The successful knowledge of an organization considered to be enhanced with the time since each instant we add further knowledge (it may be tacit or explicit or both) due to new ideas, new concept or new interpretation. Due to knowledge reusability we get qualitative knowledge, however, it reduces the effective quantity of entire knowledge.

Similar to Nonaka and Takeuchi Model [10], we can describe these conversion processes in three dimensional environments by the Fig. 2 above $[12-14,23]$. There are someprocesses in Fig. 2 which are being discussed in the next paragraphs.

Socialization which is the procedure of dealings between individuals occurs during the knowledge sharing (Nonaka and Takeuchi Model [10]) and increases due to reuse of experiences (over the time), mental models and beliefs by employees. This manner the knowledge exists in public's minds augmented due to transformation of knowledge over the time. Thus here the tacit knowledge is converted into another tacit knowledge. Moreover, due to reusability the quality of knowledge also increases with the time as a result of refinement.

Face-to-face meetings are the burning example of building tacit knowledge which is shared by people. Shared experiences are the example of informal knowledge where role of information technology is nominal. However, concept of groupware is adopted during large number of on-line meetings and interpersonal exchanges. These techniques have been using either to poise usual gathering, or to some extent alternate means.

Groupware: Two significant effects are imperative to appreciate the deployment of groupware during socialization. They are shared skills and belief. Shared skills are vital for the tacit knowledge sharing. In the current three dimensional model, shared space will be more with extra choice of reusable knowledge. This reusable knowledge increases with the increase of virtual space. Thus it helps to enhance the tacit knowledge. Reusable knowledge boosts more faith because it is a provable knowledge. Lotus Notes is a type of a groupware and may be employed for sharing of documents. Groupware also assists in the sharing of explicit knowledge.

Externalization which is the method of detaining or capturing information about knowledge (Nonaka and Takeuchi Model [10]), for example communicating to someone, writing a manuscript, sketching a Figure, demonstrating a presentation, or instructions, will be faster as a result of reuse of knowledge with the time. Therefore there will be extra knowledge accessible to institute as contrast to the Nonaka and Takeuchi Model [10].

\section{RESEARCH PROBLEM}

Objective of present work is to demonstrate the role of knowledge transformations and reuse in the three dimensional educational environments considering time as a factor in the Nonaka model by utilizing:

- How the quality and quantity of knowledge is affected based on the students' profile? 
- How the students' can adjust the knowledge in terms of availability of reusable knowledge?

- How the Analogies between Nonaka and ADRI model exist?

- How the ontology is responsible for the learning?

- How in the theory the acquisition of reusable knowledge takes place?

- Can we consider ADRI model as equivalent to revised Nonaka model for learning?

- In what way present ADRI model is more useful for students?

\section{CONTRIBUTION: REUSABILITY AND PROPOSED} KNOWLEDGE Reuse Processes IN AN EdUCATIONAL SETting

Authors [24] have submitted a method for knowledge reuse in communities of practice of e-learning in which they proposed the process of reuse of knowledge within the communities of practice by the two types of sub-processes: namely the process of reification means transformation of tacit and elicit knowledge to a novel knowledge that is elicit knowledge, and secondly by the process of indexing by applying earlier used knowledge further (as a reusable knowledge).

Using their concepts and revised Nonaka model as discussed earlier including the role of technology, present author (Fig. 3 and Fig. 4) is suggesting an interesting (revised) knowledge reuse process for educational environment.

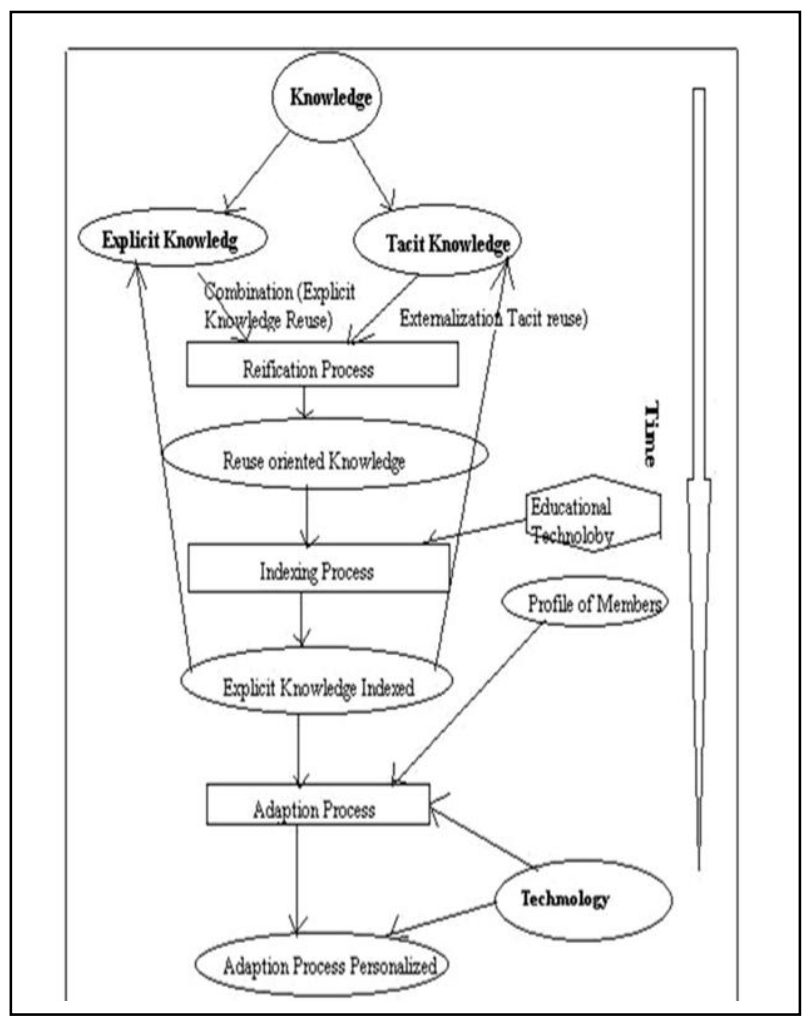

Fig. 3. Proposed Knowledge Reuse Process in an Educational Institute
If someone wants to reuse the knowledge then he or she will have to personalize it for his or her respective educational environment.

Thus one has to adapt as per his or her own profile. If a learner wants to concentrate on his or her educational activities then knowledge is to be shared or captured accordingly. According to authors [24] we can represent a generic approach and hence a generic profile model that can be applied to any persons as well as to group in the environment of communities of practice.

Since this is the problem of tacit and explicit knowledge transformation or exploitation therefore we can apply this approach to the educational environments where knowledge transfer is possible at individual as well as at group levels.

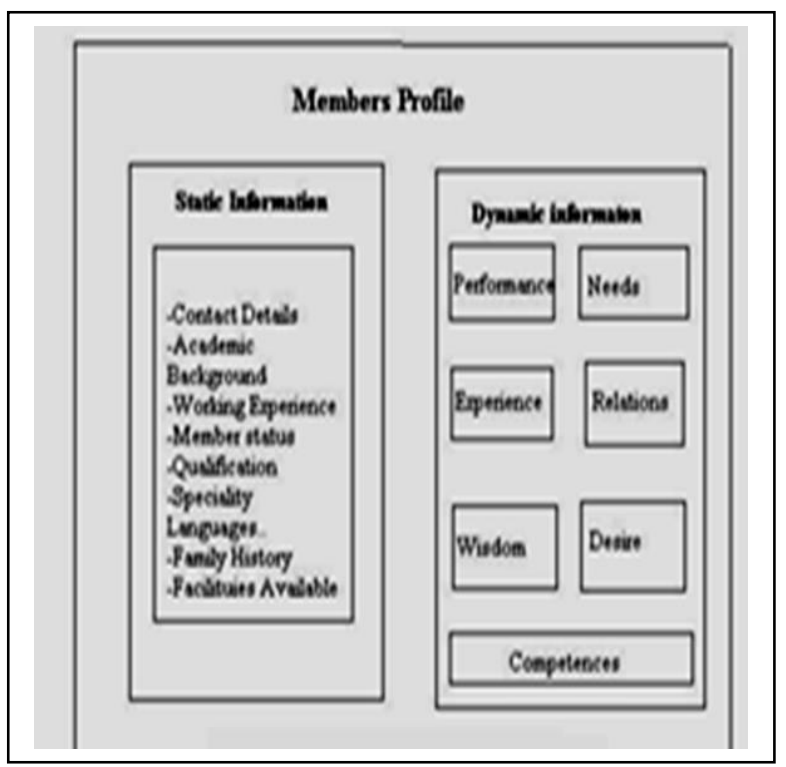

Fig. 4. Students Profile Model

Fig. 3 suggests a reification process as an approach which is responsible for deploying reusable knowledge as result we get reusable indexing process which can be further improved to achieve explicit as well as tacit knowledge. Finally the explicit or tacit knowledge can be adapted to get the personalized relevant knowledge by the students. Thus the needs of students can be personalized by the repetitive process.

Thus similar to authors [24], in the present problem one can assume two types of information in educational environments, egg static information and dynamic information (Fig. 4). Static information includes individual information like contact details, his or her academic background, qualifications, type of work experience etc while dynamic information consists of personalized behavior during individual participation in educational activities which includes knowledge sharing and knowledge capturing activities. Similar to these we propose seven dynamic elements (See Fig. 4) which can be used in educational environments, namely, needs, preferences in connection to the knowledge being related to existing resources. Other elements are relations (how to relate with a group or other learners); learning (learning scenario for the explanation), experience (learners' know-how ability), 
competences (related to cognitive attribute), wisdom (ability of making judgment) and desire (aspiration for the task) (see Fig. 4).

\section{ADRI HIGHER EDUCATION QUALITY MODEL AND REUSABILITY}

To appreciate the idea of knowledge reusability for learners, an application supported by ADRI model(Approach, Deployment, Result, and Improvement) [18] is being suggested which is recognized for the quality assertion and improvement properties in higher educational settings. It is being suggested that our revised ADRI model is similar to three dimensional Nonaka [8] model which not only consists tacit and explicit knowledge conversion processes with time; while all above mentioned knowledge reification and related processes can also be considered. It is noteworthy to quote that ADRI model is a general tool for appraisal and development [18] in many means. Current author have previously been engaged on ADRI model in explaining the varieties of features of knowledge management $[19,20]$. To deal with the present problem work of Jantti [21] has been considered which accounts the ADRI model and has the following four approaches (Fig. 5):

- An Approach means how to relate and imagine about the mapping

- Deployment means how to correlate to execute

- Results (performance) means how to observe and assess and

- Improvement means how to relate with further rectification and adjustment.

Similar to the approach to Fig. 1 and Fig. 2, present author suggesting first time Fig. 5 (see below) which consists of tacit and explicit knowledge in opposite directions as well as knowledge reusability orthogonal to both tacit and explicit knowledge. knowledge.

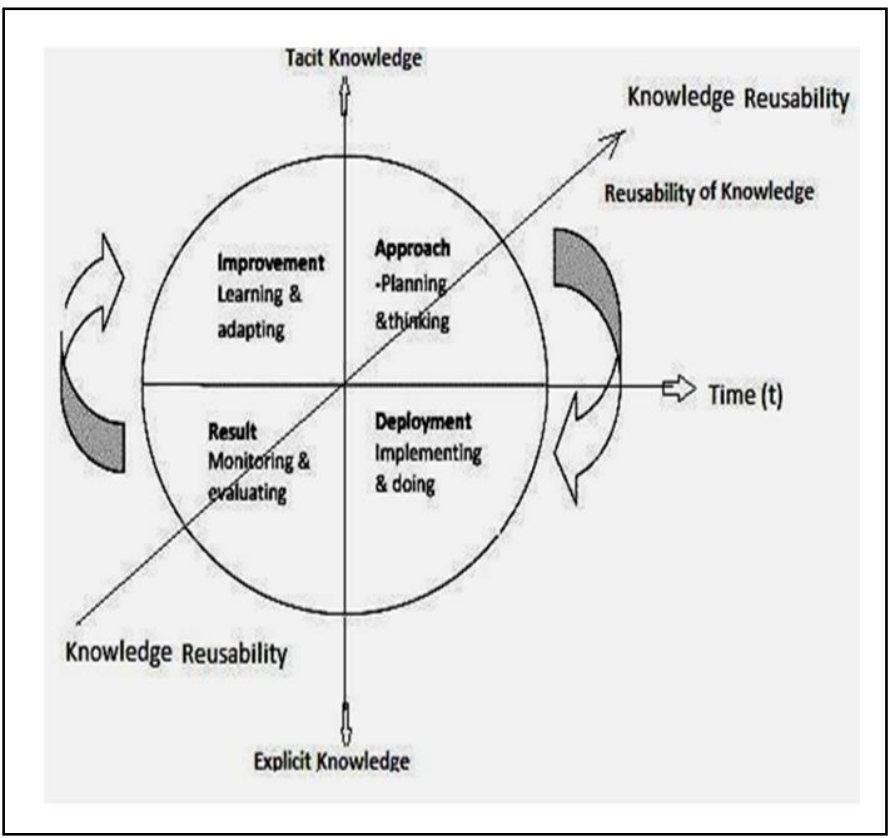

Fig. 5. Revised ADRI Model
Here we need to take a decision that what approach is to be taken up? It typically relates with expansion of goals, policies,

The first stage in the ADRI model is Approach which usually consists of imagining and scheduling jobs and therefore it corresponds to conversion from tacit to tacit principles, outcomes, map and aims. Present suggestion is that setting up of knowledge and its reuse should obviously indentify qualitative and quantitative aims and can state path to achieve the aims [18].

The second stage (Fig. 5) is operation or Deployment which tenders a dais to execute or understand tasks. It is just the combination process in the Nonaka model which is the stage that joins existing knowledge with novel produced knowledge.

Here the present author would like to suggest that presence of reusability of knowledge (with time) will generate and joins more knowledge as the time enhances and hence conversion from explicit to more focused explicit knowledge takes place.

People in the organization feel more linked with knowledge in less time. Consequently it is clear that suitable arrangement can be build at the principal step to comprehend the purpose of knowledge management and reuse [18].

The third stage (Fig. 5) is the consequence or result, which signify yield or outcome as a result of the first and second stages of knowledge administration and reuse as stated above. We should remember that important thing is that output (result stage) and goal (approach stage) should be connected mutually. Result's stage presents assessment between predictable yield and achieved yield. Present statement is that result will be more qualitative due to the application of reusable knowledge. Technology also play here significant role in the deployment because of type of tool used for displaying the results as well as reusing the data, information and knowledge. This step can offer us a possibility to inspect yield (output) and demonstrate conclusions.

The fourth and final stage is enhancement or improvement which exhibits the conclusions achieved from the above results and analysis stages. This stage recommends that what is to be needed for enhancement or improvement [22]? As outlined earlier, ADRI model is a continual progression of improvements; consequently the technique of added improvement in knowledge administration and reuse depends on the subsequent achieved ADRI cycle. Since in the earlier phase we were involved in converting tacit knowledge into explicit while in this phase we have an opportunity to transform explicit to more explicit knowledge. Thus here we are getting more focused explicit and qualitative knowledge. Here results will be highly useful and interesting if we exploit the features of Fig. 3 and Fig. 4 into the ADRI model of Fig. 5. Thus as a method of reification, indexing and adaption (by classifying into static and dynamic knowledge), a process of systematic and comprehensive learning can be developed which will be much more adequate as compared to considering only ADRI model.

In the current research we have suggested to recognize the task of the technology and reusability and related issues on the three dimensional Harsh as well as ADRI model by having the 
essential features of Nonaka and Takeuchi [10] model. Our models are not only enhancing the effective knowledge of the organization whereas it helps us in picking suitable issues such as:

- Categorizing inaccurate knowledge pertinent to the technology.

- Relate knowledge in an exacting technological state because we are more certain about the kind of knowledge which is convenient to technology.

- Categorizing and unraveling tacit and explicit knowledge further quicker as well as opportunity to translate tacit to explicit knowledge (and vice versa) speedily by the suitable employment of technology.

- Estimating the useful knowledge of the organization positively and recurrently as a result of straight effect of technology.

- Customers can have more choices to select the applicable technology appropriate to the wanted knowledge.

- It offers quicker knowledge relocation once we become sure about the technological strictures.

- Reification process which makes the knowledge exactly reusable and accountable.

- Indexing process to make enable knowledge reuse and sharing because students have a common vocabulary which could demonstrate the concrete concepts of students in learning environments. In order to demonstrate this vocabulary we need ontologies [25].

- Throughout adaptation process reuse purpose can be reassured along with the information of students' profile.

- Presence of indexing process at an early stage results into available reusable knowledge in the beginning.

- Fig. 6 can identify the actor and analysis methodology in conjunction with Nonaka model which further facilitates the learning matrix.

\section{KNOWLEDGE MANAGEMENT IN SOFTWARE ENGINEERING AND OUR PRESENT MODELS}

Since the software process is a complex, cooperative and incessant improvable procedure, therefore People, technology, organization and connected measures are the most significant features of software making and growth. Quality is not merely a concern for the software expansion while at the same time processes involved in software creation are likewise significant. Due to the insertion of knowledge reusability and time, it becomes extra intricate to choose the appropriate technology. Computer based devices can resolve the intricacy of the software processes to some degree. Our three dimensional representation can improve the opportunity of enhanced understanding of the skills of software development since identification, indexing and adaption of reusable components can shape the quality of the organizations.

\section{LATEST WORK ON BEST PRACTICES IN HIGHER EDUCATION}

Butnariua and Milosanb [7] outlined and argued the professional abilities, skills, training and competences necessary in line to realize best practices and to thrust onward the development in knowledge management within Higher Education. They proposed a diagram through which they could represent the requirements of a methodology for change in knowledge, attitude, and or behavior (See Fig. 6). In the present work it has been shown that this Fig. works similar to ADRI model as discussed above like Approach, Deployability, Results, Improvements and arrow of Feedback.

Fig. 6 suggest that the ADRI model already included in the best practices which could be desired at a University level.

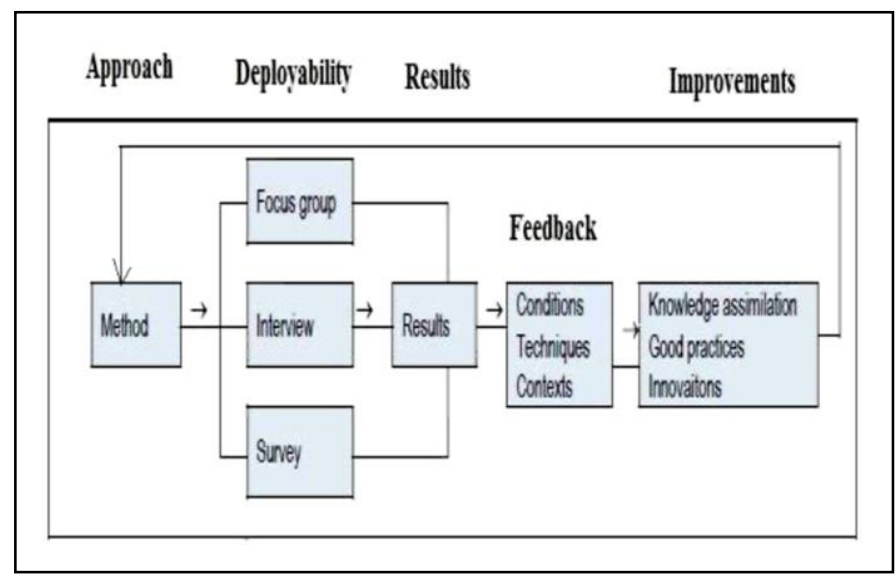

Fig. 6. Requirements of a methodology for change in knowledge, attitudes and or behavior (Reference 7)

As the authors suggested [7], a university may be the source of creating skills and capability through information and coordinate with the help of activities like Fig. 6 which fulfill are our requirements. Off course application of these activities involve the intellectual psychology. We must be aware of the fact that the teaching activities involve an intellectual analysis and imaginative components which should be as per needs of the society [7].

Thus approach of construction and humanizing the excellence of the education movement comprise a standard of continuous innovation as the time changes.

\section{CONCLUSION}

In the present work author has discussed knowledge management model which involves reuse and time as an orthogonal to each other. It has been suggested logically that how tacit and explicit knowledge (including reusable) advanced and translated into non-reusable and reusable improved knowledge by the application of the suitable consideration of reification process, indexing, adaptation and off course application of technology. We appreciate that further helpful reusable knowledge may be exploited if one can corelate amended knowledge management model (which consider the explicit role of reusability and technology) to the software expansion case studies or plans. 
As a result of novel three dimensional model extra space and knowledge will not only be accessible while new knowledge (including reusable knowledge) is exchangeable from explicit to tacit and vice versa. Ultimately added choice of new kind of tacit and explicit knowledge will be obtainable. It should be noted here that the role of the technology such as visualization instruments, browsable video/audio of presentations are some of the fine examples which could be appropriately exploited for the learning in a reusable environment.

As a consequence of application of reusability of knowledge in a specified technological environment, not merely quality of knowledge while the efficiency will also be improved. Therefore by the appropriate amalgamation of metrics with the technology in a three dimensional environment, reusability may be achieved to an immense amount. In addition, best practices in higher education environment has also been briefly discussed which reflects the use of ADRI model. Thus the current research can help us in improved way in the deployability and accomplishment of the reusable components. We can think in the future to have an entire new technological structure which could play a vital part in picking the needed reusable knowledge components.

\section{ACKNOWLEDGMENT}

Author would like to thank to his institution's Chairman cum Chief Executive Officer Shri Amit Sharma (Amritsar College of Engineering \& Technology, Amritsar) for supporting this research work by providing a good research environment and related facilities.

\section{REFERENCES}

[1] G. M. Steyn, "Creating Knowledge Through Management Education: A Case Study of Human Resources" Management. Education, vol. 123(3), pp. 514-531, 2002.

[2] M. Martensson, "A critical review of knowledge management as a management tool," Journal of Knowledge Management, vol. 4(3), pp. 204-212, 2000.

[3] K. Eginton, "Knowledge management-law firms can do it too. AustralianLaw Librarian", vol. 6, pp. 247-255, 1998.

[4] G. von Krogh, S. Spaeth, S. Haefliger, "Knowledge Reuse in Open Source Software: An ExploratoryStudy of 15 Open Source Projects," System Sciences, 2005 [HICSS '05. Proceedings of the 38thAnnual Hawaii International Conference pp.198b,198b, 03-06 Jan. 2005].

[5] G. Hedlund, "A Model of Knowledge Management and the Nform Corporation." Strategic Management Journal vol. 15, pp. 73-90, 1994.

[6] K. Kusunoki, and I. Nonaka, Akiya Nagata "Organizational Capabilities inProduct Development of Japanese Firms: A Conceptual Framework and EmpiricalFindings." Organizational Science vol. 9(6), pp. 699-718 1998.

[7] Monica Butnariu and Ioan Milosan, Best practices to increase progress in knowledge management Procedia - Social and Behavioral Sciences 62, pp. $739-743,2012$

[8] I. Nonaka, "The Knowledge Creating Company," Harvard Business Review 69, 96-104 (November-December 1991).

[9] I. Nonaka and N. Konno, "The concept of 'Ba': building a foundation for knowledge creation”, California Management Review, Vol.40, No.3, Spring, pp. 40-54, 1998.

[10] I. Nonaka and H. Takeuchi, The knowledge-creating company. How
Japanese companies create the dynamics of innovation, Oxford University Press, Oxford, 1995.

[11] I. Nonaka, "A dynamic theory of organizational knowledge creation", Organization Science, Vol.5, No.1, February, p. 14, 1994.

[12] O. K. Harsh, "Data, Information and Knowledge \& Reuse Management Techniques", World Congress in Engineering held in London from July 2 to July $4,2007$.

[13] O. K. Harsh, "Explicit Knowledge Management and Reuse", Presented in KMO workshop held in Lecee, Italy on Sept 10-11 2007.

[14] O. K. Harsh, "Reusable Data, Information, Knowledge and Management Techniques", Journal of Knowledge Management Practice vol 9(3), 2008.

[15] O. K. Harsh, "Three Dimensional Knowledge Management And Explicit Knowledge Reuse" Journal of Knowledge Management Practice, Vol.10 , No. 2, June 2009

[16] M. Polanyi, "The Tacit Dimension," Knowledge in Organizations, L. Prusak, Editor, Butterworth-Heinemann, Woburn, MA 1997.

[17] R. Bose, "Customer Relationship Management: Key Components for IT success", Industrial Management \& Data Systems, vol. 102 (2), pp. 8997, 2001.

[18] B. A. Abuid, ADRI - Self assessment model for teaching and learning, presented at 2nd international conference on global trends and challengein higher education and quality assurance, 12-13 June, 2010, Oman.

[19] A. Alani, O. K. Harsh, and S. Iqbal, Role of Information and CommunicationTechnology on Knowledge Management in a higher educational environment, presented at International Conference on Information and Communication Technology, March 22-23, 2009, Middle East College of Technology, Muscat, Oman.

[20] A. Alani, O. K. Harsh, and S. Iqbal, "Qualitative Knowledge Management and Knowledge Reuse in Higher Educational Setting", presented at the second international conference on quality and higher education, Muscat, Oman, June 12 to June 13, 2010.

[21] M. H. Jantti, Minding your own business: can a business excellence Framework translate to the education sector? in Proc. Quality conversations on the Annual Higher Education Research andDevelopment Society of Australasia Conference, presented at 25th Annual International HERDSA Conference, Perth, 7-10 July, 2002.

[22] Quality Frameworks. (2006). Reflections from Australian Universities. edited by Jeanette Baird. Australian Universities Quality Agency. [Online]. Available At: http://www.auqa.edu.au. Accessed on 10th Sep 2009.

[23] O. K. Harsh "Knowledge Reuse and Management in the Information Systems", A thesis submitted for the degree of Doctor of Philosophy of the University of New England, March, 2010.

[24] Lamia Berkani and Chikh, Azeddine, A Processfor knowledge reuse in communities of practice of e-learning. Procedia Social and Behavioral Sciences Vol.2, pp. 4436-4443, 2010.

[25] T. R. Gruber, A Translation Approach to Portable Ontology Specifications. In KnowledgeAcquisition, Vol. 5(2), pp. 199-220, (1993).

[26] O. K. Harsh. and Sharma, Sanjiv, Software Management and Reuse: Knowledge Perspective, International Journal of Software and Web Sciences (IJSWS), Vol.1 (2), 50-53,2013.

[27] O. K. Harsh and Banga, Rainu, Qualitative Knowledge Management and Reuse in Software Engineering Environment, International Association ofScientific Innovation and Research (IASIR), Vol.6 (1), 14-17, 2013.

[28] O. K.Harsh, Qualitative Knowledge Management and Reuse in Software Engineering Environment, International Journal ofSoftware and Web Sciences (IJSWS), 14-139, Vol. 7(1), 52-56, December 2013-February 2014.

[29] Aboubakr, A. Moteleb, and Mark Woodman, Notions of Knowledge Systems: A Gap Analysis, Electronic Journal of KnowledgeManagement, Vol. 5 (1), 55-62, 2007 